\title{
Analytic Hierarchy Process Expansion for Innovation Performance Measurement Framework
}

\author{
Song-Kyoo Kim \\ Washington SyCip Graduate School of Business, Asian Institute of Management, 123 Paseo de Roxas, Makati, 1230, Philippines \\ Correspondence should be addressed to Song-Kyoo Kim; SKim@aim.edu
}

Received 6 November 2012; Revised 7 January 2013; Accepted 29 January 2013

Academic Editor: You-Rong Li

Copyright (C) 2013 Song-Kyoo Kim. This is an open access article distributed under the Creative Commons Attribution License, which permits unrestricted use, distribution, and reproduction in any medium, provided the original work is properly cited.

Innovation is a top strategic priority for the majority of companies. The need for innovation becomes more and more evident in the current corporate world, and the purpose of innovation is to create business value. The Analytic Hierarchy Process (AHP) is a structured technique for organizing and analyzing complex decisions. This paper is targeting the framework design of the innovation performance criteria and provides the general guidelines to evaluate the relationship between the criteria by using AHP expansion.

\section{Introduction}

Innovation is a top strategic priority for the majority of companies. The need for innovation becomes more and more evident in the current corporate world, and the purpose of innovation is to create business value. Western companies in particular are facing high competition due to the continuous globalization. This brings focus on making innovation more comprehensive in order to be effectively able to manage and improve it. The value of innovation can take many different forms, such as incremental improvements to existing products, the creation of entirely new products and services, or reducing costs. Enterprise is driven to survive and to grow, and in a rapidly changing market the only way to do either is to innovate effectively. But most companies are failing to keep pace in a critical part of the equation: metrics and measurement. It may be called innovation uncertainty principle as many of the ways that companies might want to measure innovation can significantly impede the innovation process, because innovation involves a venture into the unknown, and if we try to pin these unknowns down too fast we may make them harder to recognize and realize.

The Analytic Hierarchy Process (AHP) is a structured technique for organizing and analyzing complex decisions: selecting among competing alternatives in a multiobjective environment, the allocation of scarce resources, and forecasting. Although it has wide applicability, the axiomatic foundation of the AHP carefully delimits the scope of the problem environment. Based on mathematics and psychology, it was developed by Thomas L. Saaty in the 1970s and is quite often referred to as the Saaty method.

The method is mathematically simple calculations but the very practical tool. There is the homogeneity axiom states that the elements being compared should not differ by too much in the property being compared [1-3]. If this is not the case, large errors in judgment could occur. When constructing a hierarchy of objectives, one should attempt to arrange elements in clusters, so that they do not differ by more than an order of magnitude in any cluster. Usually, the AHP verbal scale ranges from 1 to 9 , or about an order of magnitude, while the numerical and graphical models of Expert Choice accommodate almost to two orders of magnitude, allowing for a relaxation of this axiom. Judgments beyond an order of magnitude generally result in less accurate and greater inconsistency in priorities.

Since, the innovation does not physically exist and is not shown as clear numbers, it is very hard to determine the measuring criteria. Even current researches [4, 5] can only suggest the survey from CEO level persons in the companies which launch the innovative products or services. In fact, 
companies launching innovative products does not mean that the companies are innovative by themselves. The survey is still a practical tool, and it is also applied in this paper to gather nonnumbered data from people, but the relationship between innovation criteria cannot be determined by the survey. In other words, the innovation performance criteria in Inputrelated, Process-related, and Output-related can be listed, but there are no indications which criteria are important than other criteria. The paper shows the guidelines of how to prioritize the innovation performance criteria based on the importance. The innovative approach by adapting one of classical decision making tools since 1970s.

The paper is targeting for framework design of the innovation performance criteria and provides the general guidelines to evaluate the relationship between the criteria by using AHP expansion. In addition, it provides the decisionmaking methods to analyze the innovation performance measurement priorities regardless of business areas.

\section{Analytic Hierarchy Process Expansion}

The Analytic Hierarchy Process (AHP) is a mathematically simple tool and can be described more effectively by using matrix in the linear algebra [6]. The AHP expansion is the extended method that gives more flexible usage of the method. The classical AHP is the subset of the AHP expansion.

Let the matrix $\mathbb{C}$ be the relationship matrix within criteria and the values $u_{i, j}, i=1, \ldots, n, j=1, \ldots, n$ in the matrix indicate the value of how many times importance when the criteria $i$ compares to the criteria $j$. The AHP verbal scale ranges from 1 to 9 , or about an order of magnitude:

$$
\mathbb{C}=\left[\begin{array}{ccccc}
c_{1,1} & c_{1,2} & \cdots & \cdots & c_{1, n} \\
c_{2,1} & c_{2,2} & \cdots & \cdots & c_{2, n} \\
\vdots & \vdots & \vdots & \vdots & \vdots \\
\vdots & \vdots & \vdots & \vdots & \vdots \\
c_{n, 1} & c_{n, 2} & \cdots & \cdots & c_{n, n}
\end{array}\right]
$$

In addition, let the matrix $\mathbb{U}$ be the upper triangle matrix that shows the criteria relationships:

$$
\mathbb{U}=\left[\begin{array}{ccccc}
1 & u_{1,2} & u_{1,3} & \cdots & u_{1, n} \\
0 & 1 & u_{2,3} & \cdots & u_{2, n} \\
\vdots & \vdots & \vdots & \vdots & \vdots \\
0 & \cdots & \cdots & 1 & u_{n, n-1} \\
0 & \cdots & \cdots & 0 & 1
\end{array}\right] .
$$

According to the axioms of AHP [2] the lower triangle part of the matrix is the reflection of the upper matrix $\mathbb{U}$. From (2), the elements of the criteria matrix $c_{i, j}, i=1, \ldots, n, j=1, \ldots, n$ are as follow:

$$
c_{i, j}:= \begin{cases}u_{i, j}, & i<j \\ 1, & i=j, \\ \left(u_{j, i}\right)^{-1}, & i>j .\end{cases}
$$

To get the normalized scale for each criterion, the matrix $\mathbb{C}$ is transformed as

$$
\widehat{\mathbb{C}}=\left[\begin{array}{ccccc}
\widehat{c}_{1,1} & \widehat{c}_{1,2} & \cdots & \cdots & \widehat{c}_{1, n} \\
\widehat{c}_{2,1} & \widehat{c}_{2,2} & \cdots & \cdots & \widehat{c}_{2, n} \\
\vdots & \vdots & \vdots & \vdots & \vdots \\
\vdots & \vdots & \vdots & \vdots & \vdots \\
\widehat{c}_{n, 1} & \widehat{c}_{n, 2} & \cdots & \cdots & \widehat{c}_{n, n}
\end{array}\right],
$$

where

$$
\widehat{c}_{i, j}=\frac{c_{i, j}}{\sum_{k=1}^{n} c_{k, j}} .
$$

Let $\widehat{\mathbb{W}}$ be the diagonal matrix that contains the weight factors for each criterion. By using the elementary matrix algebra, the solution can be found as follow:

$$
\widehat{\mathbb{W}}=\frac{1}{n} \cdot \widehat{\mathbb{C}} \cdot \mathbb{q}_{[n, 1]}=\left[\begin{array}{c}
\widehat{w}_{1} \\
\widehat{w}_{2} \\
\vdots \\
\widehat{w}_{n-1} \\
\widehat{w}_{n}
\end{array}\right],
$$

where

$$
\widehat{w}_{k}=\frac{1}{n} \cdot \sum_{j=1}^{n} c_{k, j}, \quad k=1, \ldots, n
$$

Let $\mathbb{S}^{i}$ be the matrix for the subcriteria (or second-degree criteria) for the (main) criteria $i$ and be the same as the alternatives in the classical AHP. But the second-degree criteria are more flexible than alternatives. Basically, alternatives are the special case of the second-degree criteria. Since the number of the criteria is determined as $n$, the range of $i$ is $1, \ldots, n$, and the number of second-degree criteria in each criterion $i$ is $m_{i}$ :

$$
\mathbb{S}^{i}=\left[\begin{array}{ccccc}
s_{1,1}^{i} & s_{1,2}^{i} & \ldots & \ldots & s_{1, m_{i}}^{i} \\
s_{2,1} & s_{2,2} & \ldots & \ldots & s_{2, m_{i}}^{i} \\
\vdots & \vdots & \vdots & \vdots & \vdots \\
\vdots & \vdots & \vdots & \vdots & \vdots \\
s_{m_{i}, 1}^{i} & s_{m_{i}, 2}^{i} & \ldots & \ldots & s_{m_{i}, m_{i}}^{i}
\end{array}\right]
$$

where $i=1, \ldots, n$. To determine the matrix for alternative choices, similar techniques for the weight factor matrix of the criteria from (2)-(4). Let the matrix $\mathbb{V}^{i}$ be the upper triangle matrix that shows the relationships between alternative choices (or subcriteria within the criteria $i$.):

$$
\mathbb{V}^{i}=\left[\begin{array}{ccccc}
1 & v_{1,2}^{i} & v_{1,3}^{i} & \cdots & v_{1, m_{i}}^{i} \\
0 & 1 & v_{2,3}^{i} & \cdots & v_{2, m_{i}}^{i} \\
\vdots & \vdots & \vdots & \vdots & \vdots \\
0 & \cdots & \cdots & 1 & v_{m_{i}-1, m_{i}}^{i} \\
0 & \cdots & \cdots & 0 & 1
\end{array}\right]
$$


where $i=1, \ldots, n$, and

$m_{i}:=$ number of alternative choices on the criteria $i$,

$$
s_{j, k}^{i}:= \begin{cases}v_{j, k}^{i}, & j<k, \\ 1, & j=k, \\ \left(u_{k, j}\right)^{-1}, & j>k .\end{cases}
$$

To get the normalized scale for each alternative choice in the criteria $i$, the matrix $\mathbb{S}^{i}$ is transformed as

$$
\widehat{\mathbb{S}}^{i}=\left[\begin{array}{ccccc}
\hat{s}_{1,1}^{i} & \hat{s}_{1,2}^{i} & \cdots & \cdots & \widehat{s}_{1, m_{i}}^{i} \\
\hat{\boldsymbol{s}}_{2,1}^{i} & \hat{\boldsymbol{s}}_{2,2}^{i} & \cdots & \ldots & \widehat{s}_{2, m_{i}}^{i} \\
\vdots & \vdots & \vdots & \vdots & \vdots \\
\vdots & \vdots & \vdots & \vdots & \vdots \\
\hat{s}_{m_{i}, 1}^{i} & \hat{s}_{m_{i}, 2}^{i} & \cdots & \cdots & \hat{s}_{m_{i}, m_{i}}^{i}
\end{array}\right]
$$

where

$$
\hat{s}_{j, k}^{i}=\frac{s_{j, k}^{i}}{\sum_{l=1}^{m_{i}} s_{l, k}^{i}} ; \quad i=1, \ldots, n ; j=1, \ldots, m_{i} .
$$

Let $\widehat{\mathbb{F}}_{i}$ be the diagonal matrix that contains the weighted values for each alternative choice within the criteria $i$. By using the elementary matrix algebra, the solution can be found as follow:

$$
\widehat{\mathbb{F}}_{i}=\frac{1}{m_{i}} \cdot \widehat{\mathbb{S}}^{i} \cdot \mathbb{q}_{[n, 1]}=\left[\begin{array}{c}
\widehat{f}_{1}^{i} \\
\widehat{f}_{2}^{i} \\
\vdots \\
\widehat{f}_{n-1}^{i} \\
\widehat{f}_{m_{i}}^{i}
\end{array}\right], \quad i=1, \ldots, n,
$$

where

$$
\widehat{f}_{k}^{i}=\frac{1}{m_{i}} \cdot \sum_{j=1}^{m_{i}} \widehat{s}_{k, j}^{i}, \quad i=1, \ldots, n .
$$

The evaluation matrix is

$$
\Phi_{k}=\widehat{w}_{k} \cdot \widehat{\mathbb{F}}_{k}, \quad k=1, \ldots, n .
$$

The alternative choices in the classical AHP are the special case of second-degree criteria:

$$
\Phi^{*}=\sum_{k=1}^{n} \Phi_{k}
$$

The classical AHP can only cover the same alternatives for all criteria that is only one of the special cases of AHP expansion. So, it can be extended to all the different alternatives.

\section{Two Cases for AHP Expansion Application}

One of the famous cases based on AHP is introduced by Richard Ivey School of Business [7]. The case is designed to study AHP schema for MBA students. According to the case, the Vice President of A-CAT Corp. has faced the decisionmaking situation for choosing the best company within four companies based on four main criteria.

(i) Criteria: efficiency, power factor, losses, and turn ratio.

(ii) Companies: Dolphin, Boss, Freedom, and Ideal.

The case problem can be solved by the AHP easily. Basically, this classical AHP is the special case of AHP expansion. This paper uses the same data in the case to simulate AHP expansion. From (1)-(4) and data from [7],

$$
\mathbb{C}=\left[\begin{array}{llll}
1.00 & 3.00 & 0.20 & 7.00 \\
0.33 & 1.00 & 3.00 & 5.00 \\
5.00 & 0.33 & 1.00 & 7.00 \\
0.14 & 0.20 & 0.14 & 1.00
\end{array}\right]
$$

Originally, the values in the matrix $\widehat{\mathbb{C}}$ are same as the values in Exhibit 1 of the case [3]. One value in Exhibit 1 needs to be revised because of the general condition of AHP [1], and the values in the matrix $\mathbb{C}$ from (17) are correct values.

From (6) and (7),

$$
\begin{gathered}
\widehat{\mathbb{W}}=\frac{1}{4}\left[\begin{array}{llll}
0.15 & 0.66 & 0.05 & 0.35 \\
0.05 & 0.22 & 0.69 & 0.25 \\
0.77 & 0.07 & 0.23 & 0.35 \\
0.02 & 0.04 & 0.03 & 0.05
\end{array}\right] \cdot\left[\begin{array}{l}
1 \\
1 \\
1 \\
1
\end{array}\right], \\
\widehat{\mathbb{W}}=\left[\begin{array}{l}
0.30 \\
0.30 \\
0.36 \\
0.05
\end{array}\right],
\end{gathered}
$$

and (19) means each criterion has following importance ratio (round-offed values within total 1.0):

$$
\text { Efficiency }=0.30 \text {, }
$$

Power Factor $=0.30$,

Losses $=0.36$,

Turn Ratio $=0.05$.

From (9)-(11),

$$
\begin{aligned}
& \widehat{\mathbb{S}}^{1}=\left[\begin{array}{llll}
0.08 & 0.18 & 0.28 & 0.03 \\
0.23 & 0.54 & 0.28 & 0.71 \\
0.02 & 0.11 & 0.06 & 0.03 \\
0.68 & 0.18 & 0.39 & 0.24
\end{array}\right], \\
& \widehat{\mathbb{S}}^{2}=\left[\begin{array}{llll}
0.41 & 0.66 & 0.41 & 0.19 \\
0.14 & 0.22 & 0.23 & 0.58 \\
0.05 & 0.04 & 0.05 & 0.03 \\
0.41 & 0.07 & 0.32 & 0.19
\end{array}\right], \\
& \widehat{\mathbb{S}}^{3}=\left[\begin{array}{llll}
0.12 & 0.78 & 0.45 & 0.02 \\
0.02 & 0.16 & 0.25 & 0.79 \\
0.01 & 0.03 & 0.05 & 0.03 \\
0.84 & 0.03 & 0.25 & 0.16
\end{array}\right] .
\end{aligned}
$$


Because the turn ration have determined independently with any relative within companies, the values of importance are determined directly. So,

$$
\widehat{\mathbb{S}}^{4}=\widehat{\mathbb{F}}_{4}=\left[\begin{array}{c}
0.26 \\
0.23 \\
0.24 \\
0.27
\end{array}\right] .
$$

From (13) and (20)-(22),

$$
\begin{array}{ll}
\widehat{\mathbb{F}}_{1}=\left[\begin{array}{l}
0.14 \\
0.44 \\
0.05 \\
0.37
\end{array}\right], & \widehat{\mathbb{F}}_{2}=\left[\begin{array}{l}
0.42 \\
0.29 \\
0.04 \\
0.25
\end{array}\right], \\
\widehat{\mathbb{F}}_{3}=\left[\begin{array}{l}
0.34 \\
0.30 \\
0.03 \\
0.32
\end{array}\right], & \widehat{\mathbb{F}}_{4}=\left[\begin{array}{l}
0.26 \\
0.23 \\
0.24 \\
0.27
\end{array}\right] .
\end{array}
$$

From (15) and (24a)-(24b), the decision values based on AHP are determined as follow:

$$
\begin{gathered}
\Phi^{*}=0.30 \cdot\left[\begin{array}{l}
0.14 \\
0.44 \\
0.05 \\
0.37
\end{array}\right]+0.30 \cdot\left[\begin{array}{l}
0.42 \\
0.29 \\
0.04 \\
0.25
\end{array}\right] \\
+0.36 \cdot\left[\begin{array}{l}
0.34 \\
0.30 \\
0.03 \\
0.32
\end{array}\right]+0.05 \cdot\left[\begin{array}{l}
0.26 \\
0.23 \\
0.24 \\
0.27
\end{array}\right] \\
\Phi^{*}=\left[\begin{array}{l}
0.30 \\
0.34 \\
0.05 \\
0.31
\end{array}\right] .
\end{gathered}
$$

Each value is mapped with each company:

$$
\begin{aligned}
& \text { Dolphin }=0.30, \\
& \text { Boss }=0.34, \\
& \text { Freedom }=0.05, \\
& \text { Ideal }=0.31,
\end{aligned}
$$

and Boss is the first choice to select the company. By using the matrix algebra, the classical AHP methodology can be easily covered by the AHP expansion in this paper. The answers can be easily compared with the original case [7].

Another well-known case can be solved by using AHP expansion to compare with the original solution [8]. The company, founded in 1960, makes specialized industrial equipment. Its future success will depend on maintaining the strength of its older product lines and on generating a constant flow of new ones. The Board of Directors needs to choose someone to lead the company through the change and upheaval that implementing the consultant's plan will involve. Four persons are considered, and one person will be chosen based on the criteria:

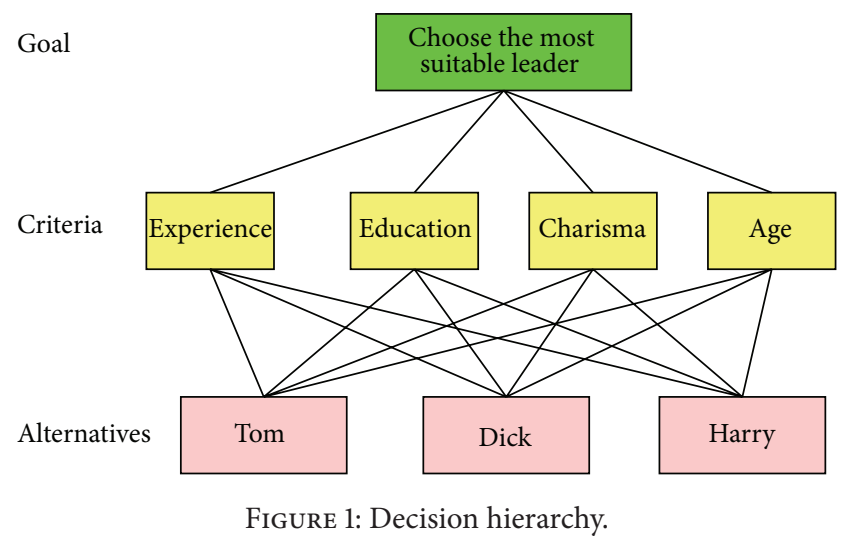

(i) Criteria: experience, education, charisma, and age.

(ii) Candidates: Tom, Dick, and Harry.

Three persons (Tom, Dick, and Harry) are considered, and the decision hierarchy is shown in Figure 1.

This paper uses the same data in the case to evaluate AHP expansion. From (1)-(4) and data from [8],

$$
\mathbb{C}=\left[\begin{array}{llll}
1.00 & 4.00 & 3.00 & 7.00 \\
0.25 & 1.00 & 0.33 & 3.00 \\
0.33 & 3.00 & 1.00 & 5.00 \\
0.14 & 0.33 & 0.20 & 1.00
\end{array}\right]
$$

From (6) and (7),

$$
\begin{gathered}
\widehat{\mathbb{W}}=\frac{1}{4}\left[\begin{array}{llll}
0.58 & 0.48 & 0.66 & 0.44 \\
0.14 & 0.12 & 0.07 & 0.19 \\
0.19 & 0.36 & 0.22 & 0.31 \\
0.08 & 0.04 & 0.04 & 0.06
\end{array}\right] \cdot\left[\begin{array}{l}
1 \\
1 \\
1 \\
1
\end{array}\right], \\
\widehat{\mathbb{W}}=\left[\begin{array}{l}
0.54 \\
0.13 \\
0.27 \\
0.06
\end{array}\right],
\end{gathered}
$$

and (28) means each criterion has the following importance ratio (round-offed values within total 1.0):

$$
\begin{aligned}
& \text { Experience }=0.54, \\
& \text { Education }=0.13, \\
& \text { Charisma }=0.27,
\end{aligned}
$$$$
\text { Age }=0.06
$$ 
From (9)-(11),

$$
\begin{aligned}
& \widehat{\mathbb{S}}^{1}=\left[\begin{array}{lll}
0.19 & 0.18 & 0.29 \\
0.76 & 0.73 & 0.64 \\
0.05 & 0.08 & 0.07
\end{array}\right], \\
& \widehat{\mathbb{S}}^{2}=\left[\begin{array}{lll}
0.16 & 0.27 & 0.15 \\
0.05 & 0.09 & 0.11 \\
0.79 & 0.64 & 0.74
\end{array}\right], \\
& \widehat{\mathbb{S}}^{3}=\left[\begin{array}{lll}
0.76 & 0.80 & 0.64 \\
0.15 & 0.16 & 0.29 \\
0.08 & 0.04 & 0.07
\end{array}\right], \\
& \widehat{\mathbb{S}}^{4}=\left[\begin{array}{lll}
0.24 & 0.23 & 0.33 \\
0.71 & 0.69 & 0.60 \\
0.05 & 0.08 & 0.07
\end{array}\right] .
\end{aligned}
$$

From (13) and (29)-(32),

$$
\begin{array}{ll}
\widehat{\mathbb{F}}_{1}=\left[\begin{array}{l}
0.22 \\
0.71 \\
0.07
\end{array}\right], & \widehat{\mathbb{F}}_{2}=\left[\begin{array}{l}
0.19 \\
0.08 \\
0.72
\end{array}\right], \\
\widehat{\mathbb{F}}_{3}=\left[\begin{array}{l}
0.74 \\
0.20 \\
0.07
\end{array}\right], & \widehat{\mathbb{F}}_{4}=\left[\begin{array}{l}
0.74 \\
0.20 \\
0.07
\end{array}\right] .
\end{array}
$$

From (15) and (33a)-(33b), the decision values based on AHP are determined as follow:

$$
\begin{gathered}
\Phi^{*}=0.54 \cdot\left[\begin{array}{l}
0.22 \\
0.71 \\
0.07
\end{array}\right]+0.13 \cdot\left[\begin{array}{l}
0.19 \\
0.08 \\
0.72
\end{array}\right] \\
+0.27 \cdot\left[\begin{array}{l}
0.74 \\
0.20 \\
0.07
\end{array}\right]+0.06 \cdot\left[\begin{array}{l}
0.74 \\
0.20 \\
0.07
\end{array}\right] \\
\Phi^{*}=\left[\begin{array}{l}
0.35 \\
0.48 \\
0.15
\end{array}\right] .
\end{gathered}
$$

Each value is mapped with each candidate:

$$
\begin{aligned}
& \text { Tom }=0.35, \\
& \text { Dick }=0.48, \\
& \text { Harry }=0.15,
\end{aligned}
$$

and Harry is the first choice to be selected as a company leader. The answers can be easily compared with the original solution [8], and the results are same with this compact analysis.

\section{Framework Setups for Innovation Performance Measurement}

One of the famous innovation metrics by Anthony [4] is suggested based on three distinct but related components Input-related, Process-related, and Output-related metrics.
Each component contains several subcriteria for evaluating the performance [4].

Input-Related Measures

$I_{1}$ : Financial resources dedicated to innovation

$I_{2}$ : Human resources focused on innovation

$I_{3}$ : Separate, protected resources for noncore innovations

$I_{4}$ : Senior management time invested in new growth innovation

$I_{5}$ : Number of patents field.

Process-Related Measures

$P_{1}:$ Process speed

$P_{2}$ : Breadth of idea-generation process

$P_{3}$ : Innovation portfolio balance

$P_{4}$ : Current growth gap

$P_{5}$ : Distinct process, tools, and metrics for different types of opportunities.

\section{Output-Related Measure}

$\mathrm{O}_{1}$ : Number of new products or service launched

$\mathrm{O}_{2}$ : Portion of revenue in core categories from new products

$\mathrm{O}_{3}$ : Portion of profit from new customers (or occasions)

$\mathrm{O}_{4}$ : Portion of profit from new categories

$\mathrm{O}_{5}$ : Return innovation investment.

The first-degree criteria are Input, Process, and Output, and the second-degree criteria are subitems in each first criterion. From (1), the matrix $\mathbb{C}$ is 3 -by-3 matrix and solves the 4by-1 matrix of $\widehat{\mathbb{W}}$. In case of second-degree criteria can be represented as the 5 -by-5 matrices $\widehat{\mathbb{S}}^{u}, u=1, \ldots, 5$. After calculating by using linear algebra from (1)-(15), four 5-by1 matrices are generated, and weighted values of criteria are contained, and the second-degree criterion that have the highest values are the most important ones.

\section{Conclusion and Further Study}

The paper proposed the enhanced version of AHP that gives enough flexibility to apply for analyzing the innovation performance measure and guidelines of how to handle the real situations. This innovative measuring methodology will provide the more suitable analysis to determine which is the more important measurement factors for managing the innovation. Even though the innovation performance can not be measured because of lack of data, the paper is valuable enough for setting up the framework of innovation performance measurement. Gathering the data from realworld industry will be the topic for a next further study. 


\section{References}

[1] T. L. Saaty, The Analytic Hierarchy Process, McGraw-Hill International Book, New York, NY, USA, 1980.

[2] T. L. Saaty, "Axiomatic foundation of the analytic hierarchy process," Management Science, vol. 32, no. 7, pp. 841-855, 1986.

[3] T. L. Saaty, "How to make a decision: The analytic hierarchy process," Interfaces, vol. 24, pp. 19-43, 1994.

[4] S. Anthony, The Innovator's Guide to Growth, Harvard Business Press, Boston, NY, USA, 2008.

[5] L. Morris, Innovation Metrics: The Innovation Process and How to Measure It, An InnovationLabs White Paper, InnovationLab. LLC, 2008.

[6] H. A. Anton and C. Rorres, Elementary Linear Algebra, John Wiley \& Sons, New York, NY, USA, 9th edition, 2005.

[7] J. R. Sharma, Decision-making at A-Cat Corp., Case Writting of Richard Ivey School of Business Foundation, 2011.

[8] T. L. Saaty, Decision Making for Leaders: The Analytic Hierarchy Process for Decisions in a Complex World, RWS, Pittsburgh, Pa, USA, 2001. 

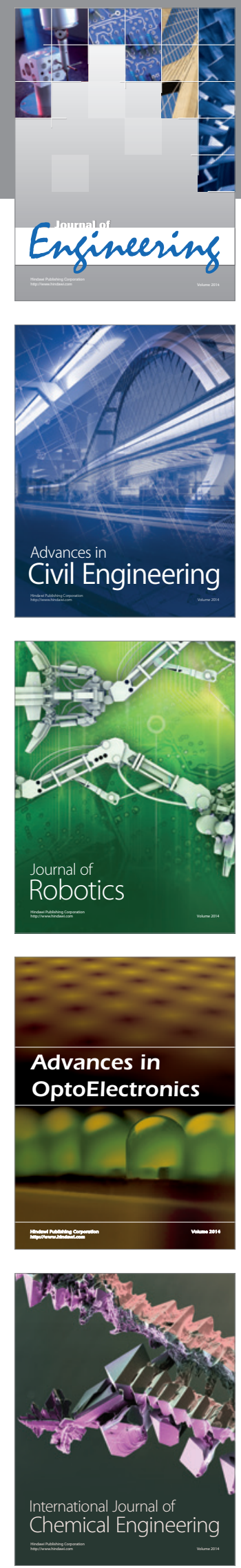

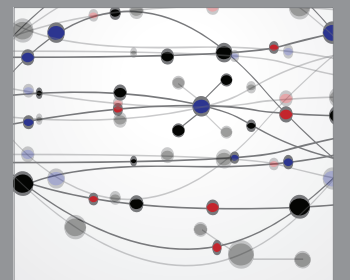

The Scientific World Journal
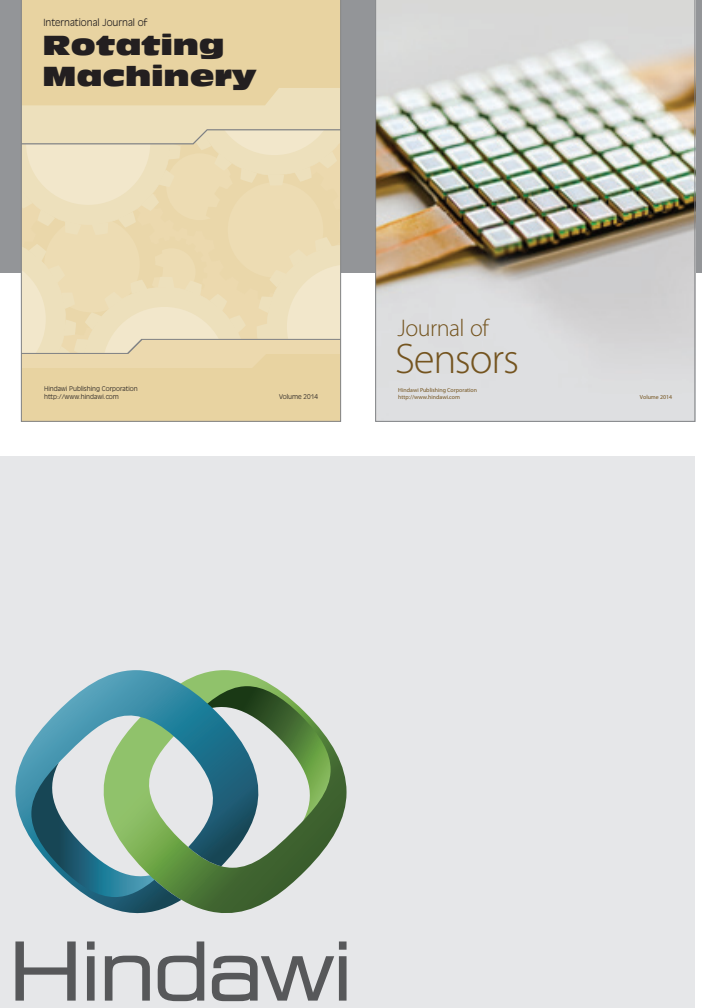

Submit your manuscripts at http://www.hindawi.com
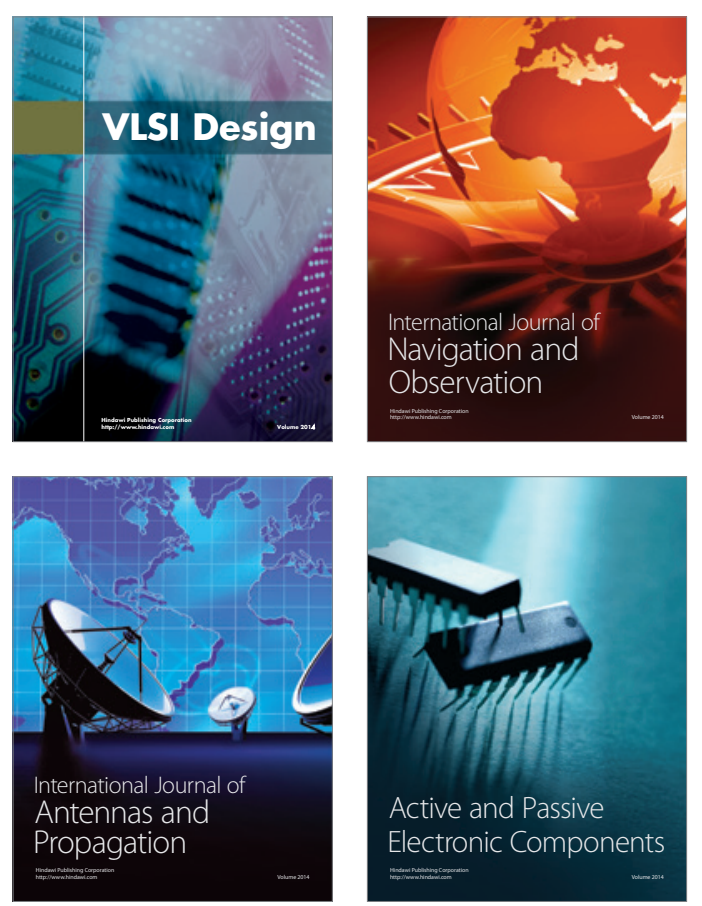
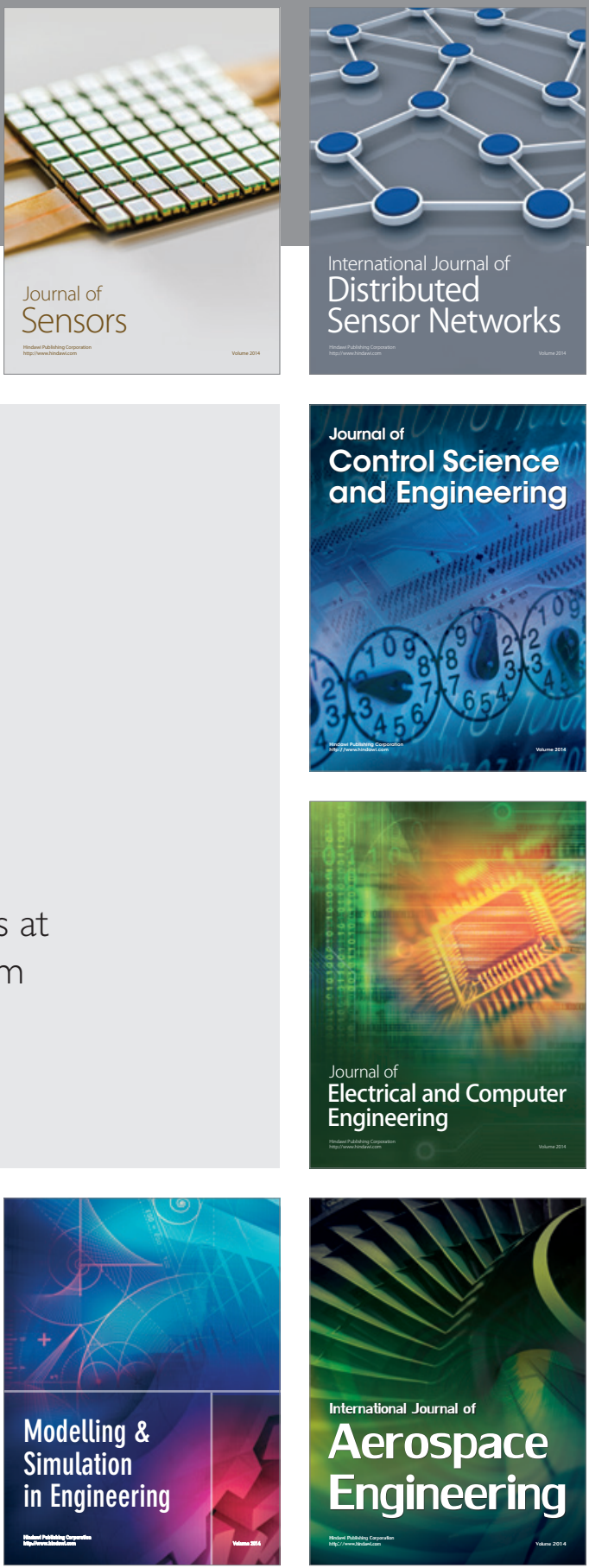

Journal of

Control Science

and Engineering
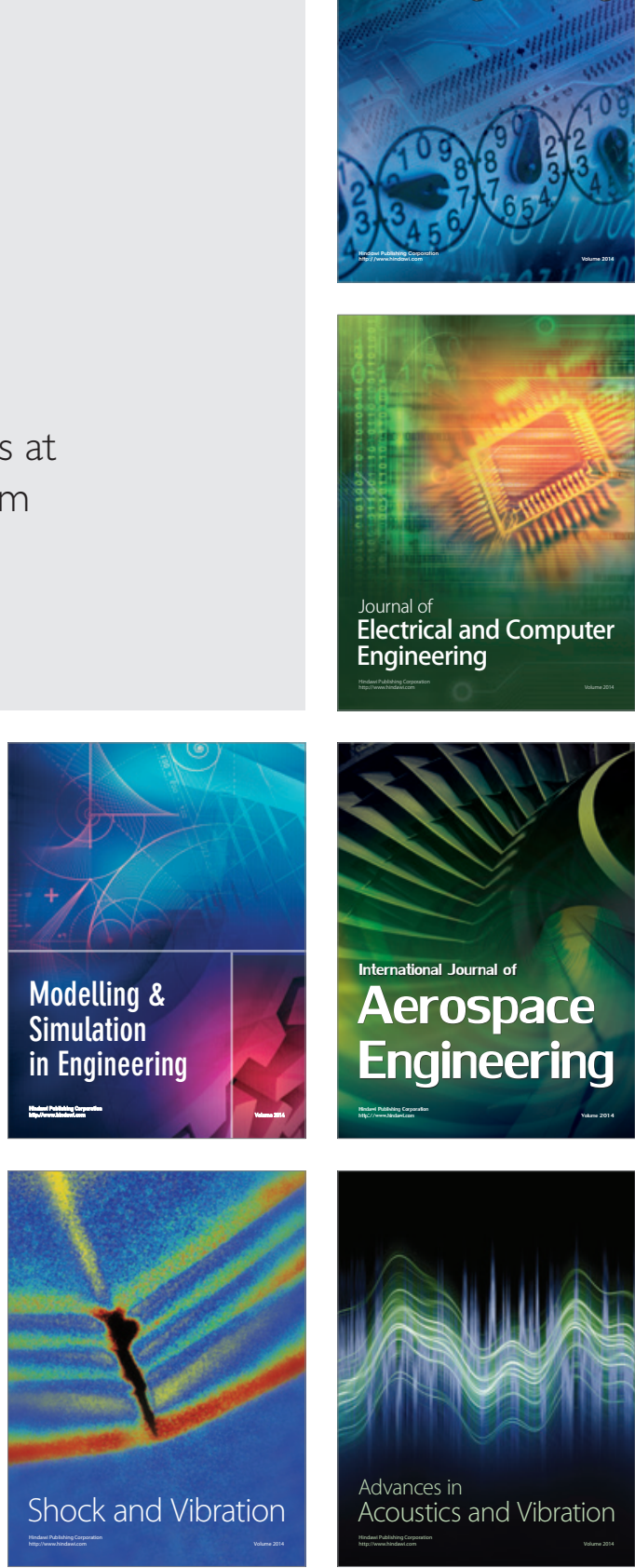